\title{
Effects of exogenous melatonin on leaf antioxidants and antioxidant capacity of kiwifruit seedling under the stress of cadmium
}

\author{
Xiaojing Huang ${ }^{1, a}$, Hui Xia ${ }^{2, b}$, Ji Liü ${ }^{3, c}$ and Dong Liang', \\ ${ }^{1}$ College of Horticulture, Sichuan Agricultural University, Chengdu, Sichuan, China \\ ${ }^{2}$ Institute of Pomology and Olericulture, Sichuan Agricultural University, Chengdu, Sichuan, China \\ ${ }^{3}$ Chengdu Academy of Agriculture and Forestry Sceinces \\ a1301621709@qq.com, bsusanxia_2001@163.com, cliujidemail@sina.com, dliangeast@sina.com
}

\begin{abstract}
Keywords: Kiwifruit; Exogenous melatonin; Cadmium stress; Antioxidant substances; Antioxidant capacity

Abstract. Using one-year-old wild Actinidia deliciosa as the experimental material, the effects of melatonin (MT) on the antioxidant system of kiwifruit seedlings under heavy metal Cd stress were studied by root irrigating method. The results showed that after MT pretreament, the contents of antioxidants (TPC, TFC, TFAC and ASA) increased in the leaves of Actinidia chinensis seedlings after $\mathrm{Cd}$ stress treatment, and the antioxidant capacity (DPPH, ABTS and FRAP) descended first and then rose.
\end{abstract}

\section{Introduction}

Cadmium $(\mathrm{Cd})$ is a heavy metal that is toxic to humans and animals and plants ${ }^{[1,2]}$. According to statistics, China's farmland cadmium pollution exceeds 13 thousand $\mathrm{hm}^{2}$, involving 25 areas in 11 provinces $^{[3]}$. The study of cadmium pollution in orchard soil is also the focus of attention at home and abroad $^{[4]}$. At present, there are many reports about the harm of heavy metal pollution to plants. Kiwifruit belongs to Actinidiaceae Actinidia Lindl and is perennial vines, has a unique flavor, nutrient-rich, high $\mathrm{Vc}$ content and high economic value ${ }^{[5]}$. Kiwifruit, as an important fruit tree resource in China has been a large number of planting ${ }^{[6]}$. Fruit growth requires a certain amount of heavy metals (such as $\mathrm{Cu}, \mathrm{Zn}, \mathrm{Fe}, \mathrm{Mn}$ and $\mathrm{Mo}$ ), these heavy metals play a very important role on the growth of fruit trees; but beyond a certain limit, it will produce toxic effects on the fruit, through the formation of reactive oxygen species ROS) produces oxidative stress in plants ${ }^{[7]}$, leading to oxidative damage to cell membrane lipid peroxidation, protein, enzymes, nucleic acids, and even plant death ${ }^{[8]}$. Therefore, it is great helpful to study the methods to improve the stress resistance of kiwifruit trees in order to maintain the normal physiological level and obtain green fruits. Melatonin (MT) is a neuroendocrine hormone secreted by pineal gland, which is N-acetyl-5-methoxytryptamine ${ }^{[9]}$, exists in the vast majority of biological organisms ${ }^{[10]}$. A large number of studies have shown that MT can not only regulate the plant growth, but also improve the plant resistant abilities to biotic and abiotic stresses, such as, high temperature, low temperature, heavy metals, chemical pollution and biological oxidation of to a certain extent ${ }^{[11]}$.

In this study, wild Actinidia deliciosa seedlings were used to study the effects of exogenous melatonin on leaf antioxidants and antioxidant capacity of kiwifruit seedling under the cadmium stress. The results will helpful to solve heavy metal stress issues by using rational MT in the kiwi cultivation and provide a theoretical basis on anti-heavy metals stress of kiwi breeding.

\section{Materials and methods}

Materials and Treatment. Seeds of wild Actinidia deliciosa was collected from Qinling, Shaanxi Province, China in September 2015, and were placed in sand for 50 days at $4^{\circ} \mathrm{C}$ and $60-70 \%$ relative humidity in winter. kept at $4{ }^{\circ} \mathrm{C}$ untill March, 2016. After variable temperature treatment at $4{ }^{\circ} \mathrm{C} 16 \mathrm{~h}$, $24^{\circ} \mathrm{C} 8 \mathrm{~h}$ for two weeks, seeds were placed at $25^{\circ} \mathrm{C}$ for $10-15$ days to germinate. We began watering the seedlings at 2-day intervals with $1 / 2$ Hoagland's nutrient solution at the two-true-leaf stage $(\mathrm{pH}$ adjusted to $6.5 \pm 0.1$ with diluted $\mathrm{HCl}$ or $\mathrm{NaOH}$ ). 
When grown up with 9-10 true leaves, seedling was irrigated with $0.1 \mathrm{~mol} \cdot \mathrm{L}^{-1} \mathrm{MT}$ solution for five times, two days once. Afterwards, seedlings were treated with $5 \mathrm{mg} \cdot \mathrm{L}^{-1}\left(\mathrm{CdCl}_{2}\right)$ for 15 days, irrigated once every two days. Middle leaves (seven to nine per plant) were sampled after $0,3,6,9$, and $12 \mathrm{~d}$. All collected tissues were immediately frozen in liquid nitrogen and stored at $-80^{\circ} \mathrm{C}$.

Enzymes Assay and Indicator Determintion. AsA content determination method adopts Ma et $\mathrm{al}^{[12]}$. TPC content determination method adopts Folin-Ciocalteu method ${ }^{[13]}$. TFC content determination method adopts Jia et $\mathrm{al}^{[14]}$. TFAC content determination method adopts p-DMACA method $^{[15]}$. DPPH, ABTS and FRAP determination method adopt Du Guorong ${ }^{[16]}$.

Data Analysis. Analysis of variance was performed using the SPSS software (SPSS, Inc., Chicago, IL, USA). Each treatment was replicated three times. Significant differences were detected using Duncan's test at the $\mathrm{P}<0.05$ level.

\section{Results and Discussion}

Antioxidant substances. After treatment with Cd solution, TPC content in leaves of kiwifruit seedling was increased first and peaked at the $9 \mathrm{~d}$ with $2.97 \mathrm{mg} \cdot \mathrm{kg}^{-1}$ and then decreased towards, which were significant higher than those in CK all over the time. However, when pretreated with MT, the TPC content of seedling significantly increased from 6 to 9 days and peaked at $9 \mathrm{~d}$, when compared with CK increased by $97.52 \%$ and then decreased towards. But The TPC content in the leaves of $\mathrm{MT}+\mathrm{Cd}$ treatment higher than that of $\mathrm{Cd}$ all the time ( Table 1).

After treatment with Cd solution, the AsA content in leaves of kiwifruit seedling was increased firstly and then decreased, and decreased slightly at $3 \mathrm{~d}$, then increased and peaked at the $9 \mathrm{~d}$, when compared with CK significantly increased by $31.71 \%$ and then decreased towards. However, when pretreated with MT, the AsA content of seedling significantly increased when compared with CK, by 93.71\% at $9 \mathrm{~d}$, and compared with $\mathrm{Cd}$ increased by $47.07 \%$. The AsA content in the leaves of $\mathrm{MT}+\mathrm{Cd}$ treatment higher than that of $\mathrm{Cd}$ all the time ( Table 1).

Table 1 Effects of exogenous melatonin on TPC content, AsA content, TFC content and TFAC content in kiwifruit under $\mathrm{Cd}$ stress

\begin{tabular}{|c|c|c|c|c|c|c|}
\hline & & & \multirow[b]{2}{*}{$9 d$} & \multirow[b]{2}{*}{$12 \mathrm{~d}$} \\
\hline & & $0 \mathrm{~d}$ & $3 d$ & $6 \mathrm{~d}$ & & \\
\hline \multirow{3}{*}{$\begin{array}{c}\mathrm{TPC} \\
\left(\mathrm{mgGAE} \cdot \mathrm{kg}^{-1} \mathrm{FW}\right)\end{array}$} & $\mathrm{CK}$ & $1.61 \pm 0.03 \mathrm{~h}$ & $1.61 \pm 0.11 \mathrm{~h}$ & $1.60 \pm 0.06 \mathrm{~h}$ & $1.61 \pm 0.06 \mathrm{~h}$ & $1.61 \pm 0.07 \mathrm{~h}$ \\
\hline & $\mathrm{Cd}$ & $1.62 \pm 0.05 \mathrm{~h}$ & $1.75 \pm 0.03 \mathrm{~g}$ & $1.85 \pm 0.01 \mathrm{f}$ & $2.97 \pm 0.05 \mathrm{~d}$ & $3.41 \pm 0.01 b$ \\
\hline & $\mathrm{MT}+\mathrm{Cd}$ & $1.62 \pm 0.04 \mathrm{~h}$ & $1.78 \pm 0.08 \mathrm{~g}$ & $1.89 \pm 0.01 \mathrm{e}$ & $3.18 \pm 0.05 \mathrm{c}$ & $3.55 \pm 0.10 \mathrm{a}$ \\
\hline \multirow{3}{*}{$\begin{array}{c}\text { AsA } \\
\left(\mathrm{umol} \cdot \mathrm{g}^{-1} \mathrm{FW}\right)\end{array}$} & $\mathrm{CK}$ & $6.90 \pm 0.19 \mathrm{fg}$ & $6.91 \pm 0.24 \mathrm{fg}$ & $6.95 \pm 0.20 \mathrm{fg}$ & $7.00 \pm 0.12 \mathrm{f}$ & $6.90 \pm 0.21 \mathrm{fg}$ \\
\hline & $\mathrm{Cd}$ & $7.03 \pm 0.26 f$ & $6.40 \pm 0.28 \mathrm{~h}$ & $8.26 \pm 0.28 \mathrm{e}$ & $9.22 \pm 0.21 \mathrm{~d}$ & $11.7 \pm 0.09 \mathrm{c}$ \\
\hline & $\mathrm{MT}+\mathrm{Cd}$ & $6.98 \pm 0.17 \mathrm{fg}$ & $6.66 \pm 0.2 \mathrm{gh}$ & $9.07 \pm 0.06 \mathrm{~d}$ & $13.6 \pm 0.06 \mathrm{~b}$ & $14.6 \pm 0.23 \mathrm{a}$ \\
\hline \multirow{3}{*}{$\begin{array}{c}\mathrm{TFC} \\
\left(\mathrm{mgRE} \cdot \mathrm{kg}^{-1} \mathrm{FW}\right)\end{array}$} & $\mathrm{CK}$ & $6.38 \pm 0.33 \mathrm{e}$ & $6.40 \pm 0.17 \mathrm{e}$ & $6.40 \pm 0.01 \mathrm{e}$ & $6.30 \pm 0.34 \mathrm{ef}$ & $6.40 \pm 0.02 \mathrm{e}$ \\
\hline & $\mathrm{Cd}$ & $6.40 \pm 0.29 \mathrm{e}$ & $5.66 \pm 0.03 \mathrm{~h}$ & $6.09 \pm 0.03 \mathrm{fg}$ & $9.99 \pm 0.13 \mathrm{~d}$ & $10.39 \pm 0.2 \mathrm{c}$ \\
\hline & $\mathrm{MT}+\mathrm{Cd}$ & $6.39 \pm 0.01 \mathrm{e}$ & $5.89 \pm 0.15 \mathrm{gh}$ & $6.52 \pm 0.02 \mathrm{e}$ & $11.1 \pm 0.16 \mathrm{~b}$ & $11.83 \pm 0.23 \mathrm{a}$ \\
\hline \multirow{3}{*}{$\begin{array}{c}\text { TFAC } \\
\left(\mathrm{mgCE} \cdot \mathrm{kg}^{-1} \mathrm{FW}\right)\end{array}$} & $\mathrm{CK}$ & $0.64 \pm 0.01 \mathrm{~h}$ & $0.63 \pm 0.02 \mathrm{~h}$ & $0.64 \pm 0.01 \mathrm{~h}$ & $0.64 \pm 0.02 \mathrm{~h}$ & $0.64 \pm 0.02 \mathrm{~h}$ \\
\hline & $\mathrm{Cd}$ & $0.63 \pm 0.01 \mathrm{~h}$ & $0.70 \pm 0.01 \mathrm{~g}$ & $0.85 \pm 0.01 \mathrm{e}$ & $1.13 \pm 0.01 b$ & $0.93 \pm 0.00 \mathrm{~d}$ \\
\hline & $\mathrm{MT}+\mathrm{Cd}$ & $0.64 \pm 0.01 \mathrm{~h}$ & $0.73 \pm 0.01 \mathrm{f}$ & $0.92 \pm 0.01 \mathrm{~d}$ & $1.22 \pm 0.00 \mathrm{a}$ & $1.01 \pm 0.01 \mathrm{c}$ \\
\hline
\end{tabular}

Note: Data with the different letters indicate the difference is significant $(\mathrm{P}<0.05)$.

The TFC content in the leaves of $\mathrm{Cd}$ and $\mathrm{MT}+\mathrm{Cd}$ treatments showed a downward first and then upword trend and decreased to minimum at $3 \mathrm{~d}$ with $5.66 \mathrm{mg} \cdot \mathrm{kg}^{-1}$ and peaked at $12 \mathrm{~d}$ with $11.83 \mathrm{mg} \cdot \mathrm{kg}^{-1}$, increased significantly from 6 to $9 \mathrm{~d}$, when compared with CK increased by $58.57 \%$ and $76.03 \%$. However, the TFC content in MT $+\mathrm{Cd}$ treatment higher than those in $\mathrm{Cd}$ all over the time ( Table 1).

Under Cd stress, the TFAC content in leaves of kiwifruit seedling showed an upward trend and peaked at $9 \mathrm{~d}$, when compared with CK increased by $76.56 \%$ and then decreased towards. However, when pretreated with MT, the TFAC content of seedling significantly increased when compared with $\mathrm{Ck}$, by $90.63 \%$ at $9 \mathrm{~d}$ and the TFAC content in $\mathrm{MT}+\mathrm{Cd}$ treatment higher than those in $\mathrm{Cd}$ all over the time ( Table 1).

Antioxidant ability. The ABTS in the leaves of $\mathrm{Cd}$ and MT $+\mathrm{Cd}$ treatments was decreased firstly and then increased, increased significantly from 6 to $9 \mathrm{~d}$ and peacked at $12 \mathrm{~d}$, when compared with CK 
increased by $21.65 \%$ and $32.13 \%$. The ABTS in Cd treatment lower than those in MT+Cd all over the time ( Figure 1A).
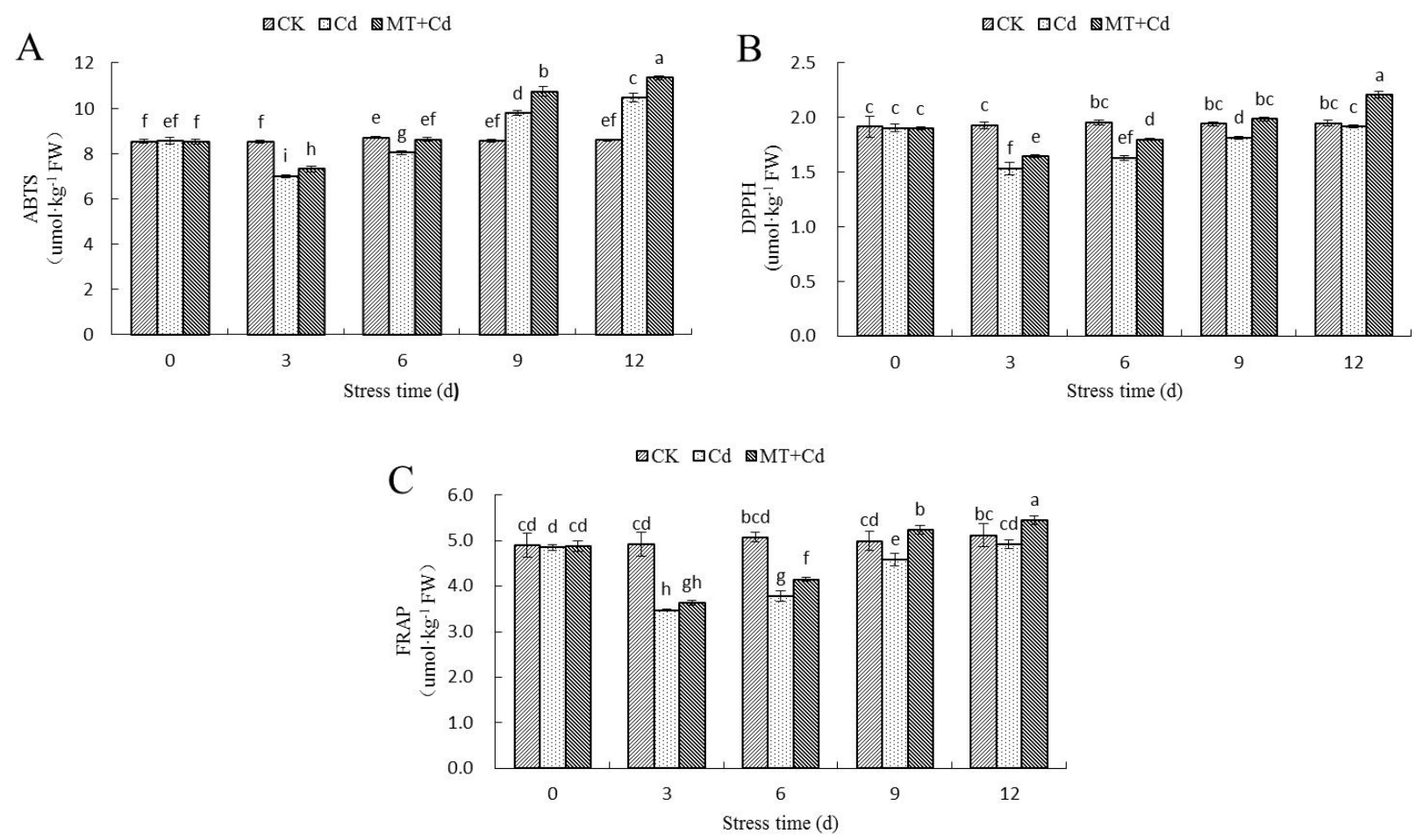

Figure.1Effects of exogenous melatonin on antioxidant ability of kiwifruit seedlings under Cd stress Note: Data with the different letters indicate the difference is significant $(\mathrm{P}<0.05)$.

Under Cd stress, the DPPH in leaves of kiwifruit seedling showed a downward trend and decreased minimum at $3 \mathrm{~d}$, when compared with CK decreased by $20.83 \%$ and then increased towards and peaked at $12 \mathrm{~d}$. However, when pretreated with MT, the DPPH of seedling significantly decreased when compared with $\mathrm{Ck}$, by $15.03 \%$ at $3 \mathrm{~d}$ and then increased. The DPPH in Cd treatment lower than those in $\mathrm{Ck}$ all over the time ( Figure 1B).

After treatment with Cd solution, the FRAP in leaves of kiwifruit seedling was decreased firstly and then increased and decreased minimum at $3 \mathrm{~d}$, when compared with $\mathrm{CK}$ decreased by $29.21 \%$ and then increased and peaked at the 12d. But the FRAP in Cd treatment lower than those in Ck all over the time. When pretreated with MT, the FRAP of seedling significantly higher than those in $\mathrm{Cd}$ treatment, and peacked at $12 \mathrm{~d}$, when compared with CK increased by $6.45 \%$ ( Figure 1C).

\section{Conclusions}

Secondary metabolites such as phenols may be involved in the scavenging of reactive oxygen species as the second line of defense under adverse circumstances ${ }^{[17]}$. The results showed that the content of antioxidant substances in the leaves of kiwifruit seedlings decreased first and then increased after $\mathrm{Cd}$ stress, and increased significantly at $9-12 \mathrm{~d}$. It can be speculated that phenolic compounds as the second line of defense, opened the self-protection model. Under the action of exogenous MT, the TPC 、 TFC and TFAC contents continued increased. At the same time, the AsA content was also increased. DPPH, ABTS and FRAP are 3 common methods for the evaluation of antioxidant activity by colorimetric assay ${ }^{[16]}$. In this study, these three methods were used to determine the antioxidant capacity of the leaves of kiwifruit seedlings under Cd stress. The results showed that the antioxidant ability of the seedlings was enhanced, while the exogenous MT treatment significantly increased the antioxidant capacity. The results indicated that exogenous MT could improve the antioxidant and antioxidant ability of kiwifruit and alleviate the damage of kiwifruit under stress conditions. 


\section{References}

[1] M.C. Dias: Cadmium toxicity affects photosynthesis and plant growth at different levels, Acta Physiologiae Plantarum. Forum Vol.35 (2013), p.1281

[2] P.C. Nagajyoti and K.D. Lee: Heavy metals occurrence and toxicity for plants: a review, Environmental Chemistry Letters. Forum Vol.8 (2010), p.200

[3] R.L. Pang and R.P. Wang: Pollution status of cadmium in agricultural soils and analysis of pollution ways, Tianjin Agricultural Sciences. Forum Vol.22 (2016), p.88 (in Chinese).

[4] F.J. Peryea: Heavy metal contamination in deciduous tree fruit orchards: Implications for mineral nutricnt management, Acta Hort. Forum Vol.564 (2001), p.32

[5] H.W. Huang: Research progress of Kiwifruit. M. Beijing: Science Press. (2000), in Chinese.

[6] X.B.Xu and Q.M. Zhang: Study and utilization of Actinidia germplasm resources in China, Journal of Botany. Forum Vol.20 (2003), p.649 (in Chinese)

[7] S.M. Gallego and M.P. Benavides: Effects of heavy metal ion excess on sunflowerleaves:evidence for involvement of oxidative stress, Plant Science. Forum Vol.121 (1996), p.153

[8] L.S. Chen and X.H. Liu: Mechanism of heavy metal toxicity and resistance in fruit trees, Journal of Fujian Agriculture And Forestry University (NATURAL SCIENCE EDITION). Forum Vol.30 (2001), p.463 (in chinese)

[9] Y. Zhao and D.H. Wang: Research progress of melatonin in plants, Northwest Journal of Botany. Forum Vol.34 (2014), p.203 (in chinese)

[10] A.R. Tilden and M.A. Becker: Melatonin production in an aerobic photosynthetic bacterium: An evolutionarily early association with darkness, Journal of Pineal Research. Forum Vol.22 (1997), p.103

[11] F. Xu and H.P. Zhou: Study on plant melatonin and its stress tolerance, Genomics and Applied Biology. Forum Vol. 32 (2013), p.264 (in chinese)

[12] F. Ma and L. Cheng: The sun-exposed peel of apple fruit has higher xanthophyll cycle-dependent thermal dissipation and antioxidants of the ascorbate-glutathione pathway than the shaded peel, Plant Science. Forum Vol. 165 (2003), p.825

[13]V.L. Singleton and J.A. Rossi: Colorimetry of total phenols with phosphomolybdic phosphotungstic acid reagents, Am J Enol Viticult. Forum Vol.16 (1965), p.153

[14] Z. Jia and M. Tang: The determination of flavonoid contents in mulberry and their scavenging effects on superoxide radicals, Food Chem. Forum Vol.64 (1999), p. 557

[15] Y.G. Li and G. Tanner: The DMACA-HCl protocol and the threshold proanthocyanidin content for bloat safety in forage legumes, Sci Food Agr. Forum Vol.70 (1996), p.92

[16] G.R. Du: Analysis of antioxidant activity and antioxidant activity of kiwifruit, persimmon and apple fruits, D. Northwest Agriculture and Forestry University. (2009) (in chinese)

[17] A. Fini and L. Guidi: Drought stress has contrasting effects on antioxidant enzymes activity and phenylpropanoid biosynthesis in Fraxinus ornus leaves: An excess light stress affair, Journal of Plant Physiology. Forum Vol.169 (2012), p.936 